\title{
REDES DE RELACIONAMENTO E A BUSCA DE AFETIVIDADE INSTANTÂNEA: UMA ANÁLISE SEMIÓTICA
}

Roseli Lourdes Gomes (UNISA)

Resumo: Com a Web 2.0, houve a difusão das redes sociais e, com elas, desenvolveram-se os sites de relacionamento e suas redes. Esse fenômeno midiático e tecnológico continua transformando as relações humanas, especialmente as afetivo-amorosas. Este artigo pretende, como objetivo geral, discutir a afetividade nas redes sociais de relacionamento contemporâneas, com base no estudo de caso da rede Par Perfeito - que é atualmente a maior rede de relacionamento no mercado brasileiro. Como objetivos específicos, visamos, em primeiro lugar, analisar semioticamente as narrativas de apresentação dos inscritos do sexo masculino na faixa etária acima de cinquenta anos, utilizando três perfis recortados da rede social selecionada; em seguida, compreender, por meio das categorias discursivas mais recorrentes nos filtros elaborados pelos inscritos, o que eles mais buscam e, por fim, debater a forma como as categorias discursivas mais recorrentes e as narrativas depreendidas dos perfis contribuem para a formação de uma afetividade instantânea. Como arcabouço teórico, utilizaremos a semiótica da Escola de Paris, em particular Greimas e Courtés (2008) e Greimas e Fontanille (1994). Como prevê a teoria semiótica, o plano do conteúdo é tripartido em nível fundamental, narrativo e discursivo, e, como metodologia, exploraremos esses níveis para apreendermos as oposições mínimas de sentido, a narratividade e as categorias discursivas, bem como as modulações passionais mais recorrentes dos perfis selecionados sobre o critério da pertinência. Como resultados parciais, verificamos existirem perfis enunciados mais passionais e mais passionalizados, isto é, a paixão construída a partir do enunciador e a paixão construída a partir do enunciatário.

Palavras-chave: Afetividade; Rede de relacionamento; Semiótica.

Abstract: With the Web 2.0, there was the spread of social networks and, with them, have developed social networking sites and their networks. This media and technological phenomenon continues to 
transform human relations, especially the affective-loving. This article aims, the general objective, discuss the affectivity in the social networks of contemporary relationship, based on the network case study Perfect Pair - which is currently the largest network of relationships in the Brazilian market. The specific objectives, we aim, first, semiotically analyze the presentation of narratives of male subscribers aged over fifty, using three cut profiles of the selected social network; then understand, by means of the most recurrent discursive categories in the filters produced by subscribers, what they most seek and finally discuss how the most recurrent discursive categories and inferred narratives profiles contribute to the formation of affectivity instantaneous. As a theoretical framework, we use the semiotics of the School of Paris, in particular Greimas and Courtes (2008) and Greimas and Fontanille (1994). As expected the semiotic theory, the content of the plan is tripartite in fundamental level, narrative and discursive, and as a methodology, we will explore these levels to apprehend the minimum oppositions of sense, narrative and discursive categories as well as the most recurrent passionate modulations selected profiles on the criterion of relevance. As partial results, we see any profiles listed more passionate and more passionalizados, that is, the passion built from the enunciator and passion built from enunciatee.

Keywords: Affection; Network of relationships; Semiotics of passions.

\section{INTRODUÇÃO}

Um fenômeno dos dias atuais é a presença frequente de pessoas com idades acima de cinquenta anos em sites de relacionamento e suas respectivas redes. Diante disso, podemos perguntar: por que essas pessoas procuram relacionamentos afetivos em ambientes não tradicionais, utilizando, por exemplo, as redes de relacionamento para essa busca? Algumas das hipóteses que podem responder a essa questão indicam a praticidade, a abreviação dos 
vínculos afetivos e emocionais e a pseudossegurança que os ambientes virtuais apresentam. Todavia, a questão continua aberta, e, para ela, encontramos muitos estudos sobre a afetividade e as redes de relacionamento na contemporaneidade (SALGADO, 2015; SANTAELLA, 2007; BAUMAN, 2003; dentre outros).

Com o advento da Web 2.0, houve a difusão das redes sociais e, com elas, desenvolveram-se os sites de relacionamento e suas respectivas redes. Esse fenômeno midiático e tecnológico continua transformando as relações humanas, especialmente as afetivo-amorosas. Este artigo pretende, como objetivo geral, discutir a afetividade nas redes sociais de relacionamentos contemporâneas, com base no estudo de caso da rede Par Perfeito - que é atualmente a maior rede de relacionamento no mercado brasileiro, conforme Freire (2015).

Como objetivos específicos, visamos, em primeiro lugar, analisar semioticamente as narrativas de apresentação dos inscritos do sexo masculino na faixa etária acima de cinquenta anos, utilizando três perfis recortados da rede social selecionada; em seguida, compreender, por meio das categorias discursivas mais recorrentes nos filtros elaborados pelos inscritos do público selecionado, o que eles 
mais buscam e, por fim, debater a forma como as categorias discursivas mais recorrentes e as narrativas depreendidas dos perfis contribuem para a formação de uma afetividade instantânea, na perspectiva da semiótica francesa.

Como arcabouço teórico, utilizaremos a semiótica da Escola de Paris, em particular Greimas e Courtés (2008) e Greimas e Fontanille (1994). Como prevê a teoria semiótica, o plano do conteúdo é tripartido em nível fundamental, narrativo e discursivo, e, como metodologia, exploraremos esses níveis para apreendermos as oposições mínimas de sentido, a narratividade e as categorias discursivas, bem como as modulações passionais mais recorrentes dos perfis selecionados sobre o critério da pertinência. Conforme Coelho (2011), a semiótica discursiva não se preocupa apenas com o signo, mas com a significação que se apresenta antes, durante e depois de todo e qualquer ato de leitura.

Para tanto, dividimos metodologicamente este artigo em três partes. No primeiro tópico, discutiremos os tipos de usuários das redes de relacionamento, com base em Prensky (2001), e a afetividade construída nas e pelas mídias digitais, utilizando o conceito de pós-modernidade na acepção de Santaella (1996) e a concepção semiótica de paixão na proposta de Greimas e Fontanille (1994). Segundo 
Coelho, Costa e Fontanari (2016), a perspectiva semiótica dentre as teorias do texto e do discurso é a que apresenta uma gama ampla de ferramentas teórico-metodológicas para se estudar os fenômenos discursivos, atendendo, assim, as necessidades desta pesquisa. No segundo tópico, faremos uma análise semiótica do percurso gerativo do sentido (GREIMAS; COURTÉS, 2008) de três perfis da rede social Par Perfeito, escolhidos sob o critério de pertinência e representatividade do público masculino com faixa etária acima de cinquenta anos. No terceiro tópico, apresentaremos uma proposta semiótica para analisar os enunciados que constroem a paixão a partir do enunciador, nomeados aqui de enunciados passionais, e os enunciados que constroem a paixão a partir do enunciatário, designados aqui de enunciados passionalizados.

\section{OS USUÁRIOS, AS REDES DE RELACIONAMENTO E A AFETIVIDADE}

Para entender os tipos de usuários das redes de relacionamento, podemos utilizar a tipologia proposta por Prensky (2001). Esse estudioso explica que existem, atualmente, pelo menos dois tipos de usuário das mídias digitais e de suas tecnologias em convivência: os nativos digitais e os imigrantes digitais. Os nativos digitais, segundo 
Prensky (2001), são aqueles que nasceram e cresceram com as tecnologias digitais fazendo parte de seu cotidiano, como a internet, telefone celular, videogames etc. Em geral, eles são os nascidos a partir da década de 1990, na Era da Informação, e estão inseridos nas tecnologias do século XXI. Já os imigrantes digitais são aqueles que nasceram anteriormente a esse período, sendo, portanto, posteriormente habituados aos usos e às práticas tecnológicas digitais, como, por exemplo, a internet e o computador. Desse modo, na sociedade do século $\mathrm{XXI}$, ainda convivem nativos e imigrantes digitais, 0 que futuramente pode se modificar com a predominância já visível dos nativos digitais.

Com base nessa tipologia, podemos afirmar que as pessoas com mais de cinquenta anos, sujeitos deste estudo, são os denominados imigrantes digitais. E por não encontrarmos muitos estudos sobre esse tipo de usuário, nasceu a necessidade e a relevância desta pesquisa.

Observamos que esse público de imigrantes digitais têm buscado cada vez mais as redes sociais como o veículo de comunicação mais apropriado para encontrar e estabelecer relacionamentos, em especial os afetivo-amorosos. Conforme Salgado (2015), baseado em Bauman (2003), as redes sociais com finalidade de estabelecer relacionamentos amorosos e 
afins, observando, é claro, as transformações socioculturais do século $\mathrm{XXI}$, podem ser definidas como

Os referidos sites de namoro (e afins) são centros de vendas e consumo do amor líquido em contexto digital; também são alguns dos operadores de uma, digamos, "lei da oferta e da procura amorosa" que ainda acaba por redefinir o amor, já que a tecnologia social (no caso, digital), como proposto há pouco, é um fator na equação amorosa. Isto acontece, em parte, da seguinte maneira: de fato, os sites de namoro funcionam, em primeiro momento, como supermercados de gente; e, secundária e indiretamente, do amor e de seus elementos. (SALGADO, 2015 p.50-1)

Como percebemos, há excessos consumistas que impregnam os discursos e as narrativas daqueles que participam dessas redes sociais. Assim, este trabalho entende que as redes de relacionamento constituem um campo importante para se compreender as relações humanas na contemporaneidade, principalmente pelo viés do pósmoderno, como discute Santaella (1996).

Como podemos definir pós-modernidade? Segundo Santaella (1996), otermo possuiváriasinterpretações, algumas delas baseando-se na ideia de período da história, uma vez que a expressão pós sugere um período que vem depois da 
modernidade e que, portanto, pode se opor a esta. Outros a entendem como um período posterior à modernidade, mas no sentido de uma atualização, não necessariamente de oposição a ela. Neste trabalho, consideramos a pósmodernidade como um período posterior e diferente da modernidade, mas não necessariamente se opondo a esta.

Compreendido esse posicionamento teórico, podemos entender a influência do pós-moderno nos relacionamentos construídos nas e pelas redes sociais. Isso ocorre porque as redes sociais estão influenciando na comunicação e na busca de melhorias no processo de relacionamentos afetivos, principalmente os relacionamentos entre adultos.

A fim de constatar essa afirmação, analisaremos três perfis de uma rede social direcionada para o público adulto, cuja finalidade é a de estabelecer relacionamentos, em especial, os de caráter afetivo-amorosos. Essa rede se chama Par Perfeito.

No Brasil, o site Par Perfeito foi instalado no ano de 2000, e é um dos mais utilizados e respeitados no nicho de mercado de relacionamentos on-line. Faz parte do grupo Match, que é considerado o pioneiro no serviço de encontros da internet, uma vez que foi lançado em 1995, nos Estados Unidos. 
É possível realizar um cadastro gratuito no sistema do Par Perfeito, mas, para ter acesso a algumas funcionalidades mais completas, é necessário realizar a assinatura mensal do serviço, o que constitui uma prática comum em sites comerciais $^{1}$.

Sobre a sua configuração, podemos verificar que entre as funções gratuitas está a busca refinada por contatos, permitindo a seleção de uma série de características físicas, psicológicas e sociais. Em cada página são exibidos os detalhes preenchidos pelo usuário em seu cadastro, incluindo idade, localização, tipo físico, dentre outras características, além, é claro, das informações sobre estado civil e preferências de relacionamento, dados esperados em um site desse tipo. Todavia, isso corrobora a tese de Salgado (2015, p.50), na qual o estudioso, apoiado em Bauman (2003), define que os sites de namoro são tipificados como "supermercados de gente", o que pode ser constatado em nosso corpus, pela aparência de vitrine que os perfis apresentam.

Acessando perfis de outros usuários, pode-se enviar piscadinhas, ferramenta interativa que funciona de maneira semelhante às cutucadas, da rede social Facebook. Outra ferramenta interativa presente no Par Perfeito permite

1 O custo da assinatura, conforme dados coletados em maio de 2016, é de $\mathrm{R} \$ 50,00$, uma assinatura mensal, ou $\mathrm{R} \$ 30,00$ mensais uma assinatura semestral. 
adicionar um link de acesso direto para os seus contatos prediletos, o que facilita a constituição de uma rede de contatos. Também é possível visualizar diversas fotos dos perfis cadastrados, mas o envio de mensagens personalizadas não é liberado para quem não assina a versão paga do site. Também existe uma limitação para o envio de textos pré-definidos na versão gratuita. Além do site, o acesso à plataforma pode ser realizado por meio de aplicativo em aparelho móvel (smartphone, tablet, etc.), nos sistemas Android e iOS.

Conforme dados divulgados por Freire (2015), o Par Perfeito conta atualmente com 30 milhões de usuários só no Brasil, sendo responsável pela união de aproximadamente mil casais por mês. "São 15 milhões de visitas por mês só no Brasil, vindas de 2 milhões de usuários únicos. Neste período, são trocadas 8 milhões de mensagens, 8,5 milhões de piscadinhas e 1 milhão de fotos" (FREIRE, 2015).

Além disso, segundo a mesma especialista, o Brasil registra uma média de 450 mil novos usuários por mês; destes, cerca de $80 \%$ procuram por um relacionamento sério, seja namoro ou casamento. Logo, constitui-se um nicho de mercado bastante efervescente, no qual o Par Perfeito tem uma grande atuação, o que justifica nosso interesse para 
esta pesquisa. Conforme Freire (2015) indica, o perfil médio constitui-se de "pessoas com vinte e cinco (25) a cinquenta (50) anos, moradoras das capitais e com curso superior completo - 65\% tem formação acima dessa escolaridade. São adultos que não possuem tempo para sair e encontram no site uma possibilidade de conhecer gente parecida".

Segundo dados divulgados no último censo, realizado em 2010, no Brasil, há mais mulheres do que homens; contudo, segundo Freire (2015), no caso do Par Perfeito, acontece o contrário: há mais homens do que mulheres à procura da companhia perfeita, o que não se verifica em outros países, conforme Freire (2015).

De acordo com as informações disponíveis na plataforma do Par Perfeito aos seus usuários e visitantes, a vigilância das informações é constante, ou seja, a maioria dos dados passa pela avaliação de moderadores, os quais devem liberar os conteúdos em até duas horas, desde que não infrinjam as regras de uso, como, por exemplo, fotos pornográficas ou de conteúdo explicitamente erótico, que são proibidas, bem como o cadastro de usuários com idades inferiores a dezoito anos. Essas prerrogativas atendem à legislação brasileira em vigor, que proíbe o namoro virtual e encontros envolvendo menores de idade, uma vez que o Estatuto da Criança e do 
Adolescente prevê que os menores de dezoito anos não têm autonomia jurídica e criminal sobre os próprios atos, sendo, portanto, tutelados por seus responsáveis e pelas autoridades públicas.

Sobre os perfis, é interessante ressaltar como a plataforma promove e realiza os encontros dos usuários cadastrados. O sistema faz o cruzamento das informações sobre quem é o usuário e que tipo de parceiro este procura, incluindo suas preferências, em especial as físicas (cor dos olhos, do cabelo, da pele, altura, peso etc.) e as de hábitos (fumante, praticante de atividades físicas e esportes, se tem animais de estimação, dentre outras possibilidades). Segundo Freire (2015), os níveis de compatibilidade variam de $80 \%$ a $100 \%$. Esse cálculo é algorítmico, conforme informações do próprio site Par Perfeito.

Sobre a efetividade do site em sua meta de estabelecer relacionamentos, segundo dados divulgados por Freire (2015), "todo mês, aproximadamente duas mil pessoas deixam o site por terem encontrado alguém. O motivo é informado espontaneamente aos desenvolvedores, ao encerrar o perfil". Compreendemos, assim, que o Par Perfeito, de acordo com seus dados, indica ser uma rede social eficiente, o que pode ser resultado de um efeito de 
sentido do marketing que envolve sua divulgação, bem como pode ser consequência da maior interação interpessoal propiciada pela carência humana na construção de seu afeto nas redes sociais contemporâneas - a questão permanece em aberto.

Compreendido o objeto de estudo deste trabalho, explicitemos o que se entende por afetividade nos estudos da semiótica francesa, orientação teórica que sustentará a análise no tópico seguinte. Começamos por salientar que vários teóricos discutem a importância da emoção e da afetividade nos processos de relacionamento humano: desde os gregos, com o estudo dos humores, até as mais recentes pesquisas em neurociências. Etimologicamente, o termo "afeto" vem do latim affectus, correspondendo, no português, a "sentimento terno de adesão", "afinidade", "reação de agrado ou desagrado em relação a algo ou alguém". O vocábulo "emoção" é definido como "ato de deslocar, movimentar", "agitação de sentimentos, abalo afetivo ou moral", "reação orgânica de intensidade e duração variáveis" (HOUAISS, 2014). Como podemos notar, os estudos sobre a afetividade são amplos e se estendem por diversas áreas; isso pode ser constatado ainda pela gama de sentidos e significados impregnados até hoje ao lexema "afeto". 
É possível verificar essa afirmação resgatando outros estudos para além do campo da teoria semiótica. De acordo com Damásio (1996), a emoção, por sua vez, pode ser entendida como um componente biológico do comportamento humano e um estado afetivo que comporta as diversas sensações de prazer e desprazer. Já a afetividade, de acordo com esse estudioso, tem sentido amplo, envolvendo as vivências individuais e as formas de expressão mais complexas do ser humano, como, por exemplo, a linguagem e consequentemente a escrita. Segundo Dantas (1992), a afetividade é entendida de outra forma, uma vez que, para o estudioso, existe uma relação estreita entre afetividade e inteligência, que introduz a noção de desenvolvimento afetivo em etapas nas quais afeto e cognição se integram. Dentro dessa perspectiva, a evolução da afetividade depende das conquistas realizadas no plano da inteligência e vice-versa. Como podemos notar, essas duas interpretações teóricas retomam fatores biológicos, psicológicos e sociais para construir a noção de afetividade.

A teoria semiótica, herdeira dos estudos linguísticos de Saussure (2013) e Hjelmslev (1992), propõe uma visão discursiva sobre os afetos construídos na e pela linguagem. Desse modo, as interpretações biológicas e psicológicas 
se afastam da teoria semiótica. Os componentes social, histórico e cultural, entretanto, são agregados na análise semiótica, uma vez que um discurso retoma outro do mesmo modo que o enunciado resgata outros enunciados. Nessa perspectiva, o texto é compreendido a partir de dois planos da linguagem: expressão e conteúdo. Esses planos são interdependentes, do mesmo modo que as duas faces de uma folha de papel, conforme Saussure (2013). O discurso, por sua vez, corresponde ao plano do conteúdo. Segundo Greimas e Courtés (2008), esse plano pode ser tripartido em nível fundamental, narrativo e discursivo, constituindo um percurso gerativo do sentido que vai do mais simples e abstrato (nível fundamental) até o mais concreto e complexo (nível discursivo).

Até 1980, a semiótica se preocupou em estudar a narratividade dos textos, isto é, o estado das coisas, questionando as transformações nos enunciados de estado. Dentro dessa primeira etapa dos estudos das paixões, os semioticistas verificavam como os efeitos de sentido dos arranjos modais transformariam o sujeito de estado, produzindo os efeitos passionais. Barros (1995) explica:

A descrição das paixões se fez, nessa etapa, quase exclusivamente, em termos de sintaxe modal, ou seja, de 
relações modais e de suas combinações sintagmáticas. Assim [...] a organização sintagmática de modalidades - quererser, não crer-ser e saber não poder-ser - produz o efeito de sentido 'afetivo' de amargura. (p.92)

Com a publicação da Semiótica das Paixões, de Greimas e Fontanille (1991), os semioticistas esboçaram, em paralelo ao esquema narrativo canônico (manipulação, competência, performance, sanção), um percurso patêmico, isto é, ao lado de uma ação, tem-se uma reação passional. Com isso, os estudos semióticos ganharam um maior poder teórico para elucidar os estados de alma, outrora campo inexplorável pela teoria estruturalista.

Para esse percurso patêmico, os dois semioticistas preveem uma sintaxe discursiva do sujeito passionalizado, a qual se estabelece pelas fases de constituição, disposição, emoção e moralização. As fases podem ou não seguir essa sequência, que depende da sintaxe narrativa, e isso valida a hipótese de que os percursos narrativos e patêmico são paralelos, logo, não hierarquizados entre si, uma vez que "o regime da paixão partilha com o regime da ação o mesmo tipo de constituinte das modalidades embora ele tenha seus próprios expoentes, a intensidade e a quantidade" (FONTANILLE, 2008 p.205). 
$\mathrm{Na}$ fase da constituição, temos a predisposição do sujeito aos percursos passionais em decorrência de sua espera (expectativa, prospectiva, retrospectiva). Na fase de disposição, há uma prolongação da espera da fase de constituição, o que resulta na convocação dos dispositivos modais (fazer, ser, saber, poder, querer, crer, dever). Esses modais são dinamizados e selecionados pelo uso, ou seja, a intensidade aspectual da cadeia modal e a quantidade característica do fazer patêmico. Na fase da emoção, temos o ápice do percurso patêmico; é nesse momento, por exemplo, que ocorrem as manifestações somáticas da paixão, como palidez, enrubescimento, tremor. Notamos, assim, que, diferentemente do que preveem Damásio (1996) e Dantas (1992), a emoção é uma parte do percurso das paixões, isto é, a emoção é parte do afeto, na perspectiva semiótica. E os aspectos fisiológicos decorrentes das paixões são pensados pela semiótica como manifestações somáticas de uma paixão construída no e pelo discurso. Logo, a emoção não causa o afeto, ela é parte do afeto na perspectiva semiótica, o que, como vimos, é bem distinto do apregoado nas orientações biológicas e psicológicas.

O quarto estágio é a moralização, que prevê uma avaliação externa e pode ser realizada por um observador social. É 
importante destacarmos que se a avaliação for realizada apenas e somente do ponto de vista do sujeito apaixonado, ela é apenas a manifestação de uma sensibilização que constitui uma operação na qual o sujeito discursivo se transforma no sujeito que sofre. Porém, se a avaliação for realizada por um observador social, constitui-se uma moralização. Ressaltamos, ainda, que toda moralização pressupõe simultaneamente uma sensibilização. Portanto, quem julga também sofre.

Observados esses aspectos teóricos, vamos, nos tópicos seguintes, analisar semioticamente os três perfis selecionados, tanto em seu percurso narrativo, quanto no patêmico, para com isso depreender as categorias discursivas mais recorrentes no corpus analisado.

\section{ANÁLISE SEMIÓTICA DOS PERFIS DO PAR PERFEITO: UM ESTUDO DE CASO}

Como já salientamos no tópico anterior, os perfis do Par Perfeito possuem uma estrutura lacunar que pode ser preenchida pelo usuário com as informações pessoais referentes aos seus aspectos físicos, psicológicos e sociais. Nessa análise semiótica, daremos preferência ao estudo do percurso gerativo do sentido dos enunciados presentes no seguimento denominado "Apresentação Pessoal" do perfil 
do usuário. A seguir apresentamos os perfis selecionados para este estudo com destaque à Apresentação pessoal, que se encontra na aba Sobre em sequência aos detalhes pessoais do usuário. ${ }^{2}$

\title{
Detalhes
}

"Desejo conhecer mulheres interessantes"

$\begin{array}{ll}\text { Relacionamento: } & \text { Divorciado(a) } \\ \text { Tenho filhos: } & \text { Não tenha } \\ \text { Quer filhos: } & \text { Não } \\ \text { Etnia: } & \text { Branco/Caucasiano } \\ \text { Tipo físico: } & \text { Pouco acima do peso } \\ \text { Altura: } & \mathbf{5 7 7}^{\prime \prime}(\mathbf{1 7 1} \mathrm{cm}) \\ \text { Fé: } & \text { Cristão-Católico } \\ \text { Fuma: } & \text { Não Fumo } \\ \text { Bebe: } & \text { Beba socialmente }\end{array}$

\section{Apresentação Pessoal}

\begin{abstract}
"Bom senso, presença de espirito, razoavel inteligência e cultura, amante da natureza, esportes e da vida ao ar livre. Sou muito ativo, gosto de viajar, conversar, sou um bom ouvinte. Pessoas de bem com a vida, bem humoradas, inteligentes, que sejam boa cia e desvinculadas de relacionamentos passados. Não fumantes. Favor não enviar frases prontas e de preferencia com fotos."
\end{abstract}

Figura 1. Perfil 1.

Fonte: Par Perfeito (2016).

2 A identificação dos usuários foi suprimida conforme as regras de ética e responsabilidade nos usos de dados pessoais em mídias públicas, em acordo com o marco regulatório da internet. 


\section{Detalhes}

"Sou o tipo certo do homem errado com todos os defeitos do homem certo"

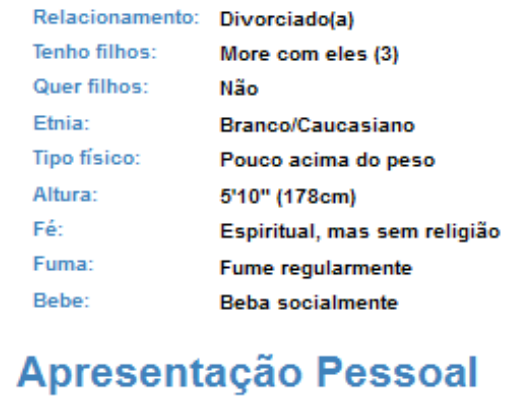

\section{Apresentação Pessoal}

"Falta de tempo, falta de atenção ou falta de zelo...é assim que perdemos pessoas "."

Figura 2. Perfil 2.

Fonte: Par Perfeito (2016).

\title{
Detalhes
}

$\begin{array}{ll}\text { Relacionamento: } & \text { Divorciado(a) } \\ \text { Tenho filhos: } & \text { More com eles } \\ \text { Quer filhos: } & \text { Não } \\ \text { Etnia: } & \text { Latino/Hispânico } \\ \text { Tipo físico: } & \text { Médio } \\ \text { Altura: } & \mathbf{5 7}^{\prime \prime}(169 \mathrm{~cm}) \\ \text { Fé: } & \text { Eu te direi mais tarde } \\ \text { Fuma: } & \text { Não Fumo } \\ \text { Bebe: } & \text { Beba socialmente }\end{array}$

\section{Apresentação Pessoal}

\begin{abstract}
"Vivendo e deixando viver "Busco uma companhia feminina do bem, situação financeira estável e resolvida com sua vida amorosa passada.Sou uma pessoa do bem, caseira, de hábitos simples, porem, que gosta das facilidades tecnologicas e desfrutar das boas coisas que a vida possa nos dar. Sou mais diurno do que noturno, acredito em Deus e sou espiritualizado, gosto de animais,, crianças e detesto mentiras, traições e falsidade. Uma mulher dentro do perfil que descrevi,com vida financeira definida e independente, determinada, de bem com a vida, buscando cumplicidade, simplicidade na forma de viver. Por favor, com fotos recentes, e tiradas de forma natural, espontanea que mostrem como voce realmente e."
\end{abstract}

Figura 3. Perfil 3.

Fonte: Par Perfeito (2016). 
Nos três perfis, observamos um sujeito modalizado pelo querer. Isso ocorre porque eles estão em disjunção com o objeto de valor: o relacionamento amoroso. Em decorrência dessa falta e pelo desejo de entrar em conjunção com esse objeto de valor, o sujeito faz sua inscrição no Par Perfeito. Desse modo, o Par Perfeito é o destinatário do usuário de sua rede. Como manipulação, o destinador promete prover o destinatário sujeito, no caso o usuário da rede, uma maior facilidade na performance, isto é, um ambiente seguro, com maior oferta e procura de contatos. É a partir dessa moeda de troca que se estabelece o contrato manipulatório entre o destinador, Par Perfeito, e o destinatário, sujeito usuário da rede. O contrato fiduciário entre esses dois actantes se estabelece e se confirma pelas crenças de segurança, facilidade e grande acesso dentro da plataforma. Esses são os elementos narrativos comuns aos três perfis analisados.

Discursivamente, eles se distinguem. Cada um propõe uma construção distinta das categorias de pessoa, tempo e espaço. O Perfil 1 organiza a categoria de pessoa de modo objetivante, uma vez que prepondera o uso da terceira pessoa do singular ou plural em detrimento do uso da primeira pessoa do singular, com apenas uma ocorrência. O Perfil 2, por sua vez, só utiliza a primeira pessoa do plural, atribuindo a marca 
enunciativa ao seu leitor, o que maximiza a subjetividade do texto. O Perfil 3 utiliza preponderantemente a primeira pessoa do singular, o que torna seu discurso subjetivo.

A categoria de espaço no Perfil 1 é construída em um lugar distante, uma vez que o enunciador utiliza um espaço não concomitante com o aqui da enunciação, construção espacial semelhante à do Perfil 2, o qual maximiza essa enunciação objetivada. O Perfil 3, por sua vez, embora não faça referência explícita ao aqui da enunciação, constrói seu discurso espacialmente mais a partir do enunciatário leitor do que os outros dois.

A categoria de tempo no Perfil 1 recupera o presente em um aspecto durativo, pois as marcas verbais estão no presente do indicativo. No Perfil 2, o tempo também é o presente, e o aspecto verbal é contínuo, uma vez que a frase retoma uma grande extensão de tempo como, por exemplo, na fórmula discursiva de um ditado. No Perfil 3, o tempo predominante é o presente, todavia temos exemplos do uso do passado em sentido anafórico como, por exemplo, no segmento: "uma mulher dentro do perfil que descrevi". Como percebemos, cada perfil constrói discursivamente e de forma diferente seu enunciado, com as marcas enunciativas e enuncivas distintas. 
Embora diferentes discursivamente, no nível fundamental, temos a mesma oposição mínima sendo articulada diversamente nos três perfis: natureza, como domínio das pulsões, e cultura, como domínio das normas e convenções sociais.

No Perfil 1, euforiza-se o domínio da natureza, como podemos perceber no segmento: "bom senso, presença de espírito, razoável inteligência e cultura, amante da natureza, esportes e da vida ao ar livre". Para este, a inteligência e a cultura podem ser razoáveis, mas o amor à natureza é determinante, pois ele é "amante da natureza".

No Perfil 2, também predomina a euforia do eixo da natureza, uma vez que, segundo o enunciador, a falta de tempo, a falta de atenção e a falta de zelo, elementos decorrentes das atividades socioculturais cotidianas do mundo capitalista, são os responsáveis pela perda das pessoas, sentimento próprio das pulsões.

No Perfil 3, prevalece o eixo da cultura, visto que o enunciador manipulador desse perfil procura aspectos socioculturais eufóricos em seu par ideal, como podemos perceber pelo seguinte excerto: "Busco uma companheira do bem, situação financeira estável e resolvida com sua vida amorosa passada". O sujeito rejeita os valores da 
vida amorosa pregressa de seu par ideal, elemento do eixo da natureza, porém, valorizando positivamente a vida econômica equilibrada.

\section{O PERCURSO PATÊMICO DOS PERFIS DO PAR PERFEITO: OS ENUNCIADOS PASSIONAIS E OS ENUNCIADOS PASSIONALIZADOS}

Com relação ao percurso patêmico, que ocorre paralelamente ao percurso gerativo do sentido, podemos afirmar que cada perfil constrói um percurso diferente. Em relação ao Perfil 1, na constituição e na disposição, encontramos um sujeito apaixonado voltado para si e para as suas qualidades. Ele enumera diversas características de sua personalidade e de sua vida social: "Sou muito ativo, gosto de viajar, sou um bom ouvinte". Da disposição à emoção, ele se mostra criterioso e faz algumas sanções negativas sobre o que seu par deve ou não ser, bem como o que pode ou não fazer: "Pessoas de bem com a vida, bem humoradas, inteligentes, que sejam boa cia [companhia] e desvinculadas de relacionamentos passados. Favor não enviar frases prontas e de preferência com fotos".

Não detectamos de fato uma moralização, mas uma sensibilização do sujeito, uma vez que ele constrói o seu discurso com base nos valores que ele aquilata para si e não para o outro, como vimos pelas suas sanções e restrições. 
Dentro de uma oposição entre enunciados que constroem a paixão a partir dos valores do enunciador, aqui nomeados de enunciados passionais, e enunciados que constroem a paixão dos valores do enunciatário, aqui definidos como enunciados passionalizados, podemos afirmar que nesse perfil prevalecem os enunciados passionais sobre os enunciados passionalizados.

No Perfil 2, verificamos, na constituição e na disposição, um sujeito apaixonado que se sente em falta, e que projeta essa falta para o mundo de forma generalizada e irrestrita. Encontramos assim um sujeito em um estado de emoção alterado que está afetado pelo mundo, e por isso utiliza o nós inclusivo (eu + tu + ele) para projetar e ampliar sua sensibilização. Aqui há uma moralização, porque o sujeito passional se vê como um ator com poder e saber para julgar por que "perdemos pessoas". Então ele cria um observador social que julga: "falta de tempo, falta de atenção ou falta de zelo". Nesse enunciado, embora tenha moralização, preponderam os enunciados passionais, uma vez que o sujeito apaixonado julga com base em seu ponto de vista.

No Perfil 3, na constituição e disposição, depreendemos um sujeito que constrói o outro, o seu objeto de desejo, de acordo com a construção do enunciatário. O outro feminino 
é projetado pelo enunciador com base em valores de cultura que ele preconiza. É por isso que o sujeito enfatiza, em duas ocorrências, a busca por uma companheira com uma "situação financeira estável", com uma "vida financeira definida e independente". Percebemos assim um sujeito apaixonado mas pouco emotivo frente aos outros dois analisados. $\mathrm{Na}$ última etapa de seu percurso patêmico, encontramos um sujeito sensibilizado que constrói seu discurso baseado em sanções de um observador social, o qual transparece no enunciado quando o enunciador cria interdições ao enunciatário conforme sua desconfiança no ser e no fazer do outro, como no excerto seguinte: "Detesto mentiras, traições e falsidade". Às vezes, esse enunciador tende ao eixo da natureza como quando ele pede "[...] fotos recentes, e tiradas de forma natural, espontânea como você realmente é". Contudo, ele está assentado predominantemente sobre o eixo da cultura; logo, ele parece ser espontâneo, mas não o é. Desse modo, nesse perfil, predominam os enunciados passionalizados frente aos passionais.

$\mathrm{Na}$ realização deste artigo, foi utilizada a pesquisa bibliográfica abrangendo leitura, análise, triagem e interpretação de livros, textos, artigos científicos e pesquisas no site de relacionamentos Par Perfeito, escolhido por 
ser o maior site de relacionamentos no País. A pesquisa bibliográfica teve como objetivo conhecer as diferentes contribuições científicas sobre os temas afetividade, rede de relacionamentos e semiótica, servindo de base para a sua elaboração dois autores e a análise semiótica dos recortes de textos dos inscritos na rede de relacionamento, seus percursos gerativos de sentidos. O desenvolvimento dessa pesquisa envolveu cinco etapas: a fase de escolha e leitura da bibliografia, resultando na conceituação e reflexão sobre os temas pós-modernidade, afetividade, rede de relacionamentos e semiótica, a importância de cada uma delas sobre a comunicação e os relacionamentos virtuais. A elaboração do artigo foi orientada pelo levantamento da obra de Algirdas Julien Greimas e Jacques Fontanille, a Semiótica das Paixões, e na escolha de três narrativas para a análise semiótica.

\section{CONSIDERAÇÕES FINAIS}

O artigo refletiu sobre a importância da afetividade e demonstrou que o afeto é determinante na construção de narrativas nos perfis dos usuários do site de relacionamento Par Perfeito e nos filtros para buscas de perfis compatíveis. Como objetivos visamos, em primeiro lugar, analisar semioticamente as narrativas de apresentação dos inscritos 
do sexo masculino com idades acima de cinquenta anos, utilizando três perfis recortados da rede social selecionada; em seguida, depreendemos, por meio das categorias discursivas mais recorrentes nos filtros elaborados pelos inscritos do público selecionado, o que eles mais buscavam e, por fim, debatemos a forma como as categorias discursivas mais recorrentes e as narrativas depreendidas dos perfis contribuíram para a formação de uma afetividade instantânea, na perspectiva da semiótica francesa.

Para tanto, dividimos metodologicamente este artigo em três partes. No primeiro tópico, discutimos os tipos de usuários das redes de relacionamento, com base em Prensky (2001), e a afetividade construída nas e pelas mídias digitais, a partir do conceito de pós-modernidade na acepção de Santaella (1996) e da concepção semiótica de paixão na proposta de Greimas e Fontanille (1994). No segundo tópico, fizemos uma análise semiótica do percurso gerativo do sentido (GREIMAS; COURTÉS, 2008) de três perfis da rede social Par Perfeito, escolhidos sob o critério de pertinência e representatividade do público masculino com faixa etária acima de cinquenta anos. No terceiro tópico, apresentamos uma proposta semiótica para analisar os enunciados que constroem a paixão a partir do enunciador, nomeados aqui de enunciados passionais, e os enunciados que constroem 
a paixão a partir do enunciatário, designados aqui de enunciados passionalizados. Como resultados parciais, concluímos que existem perfis enunciados mais passionais e mais passionalizados, isto é, a paixão construída a partir do enunciador e a paixão construída a partir do enunciatário.

\section{REFERÊNCIAS}

BARROS, Diana Luz Pessoa de (1990). Paixões e apaixonados: exame semiótico de alguns percursos. Cruzeiro semiótico. Porto, (11/12), 60-73. BAUMAN, Zygmunt (2001). Modernidade líquida. Plínio Dentzien (Trad.). Rio de Janeiro: Zahar Editores, p.11-12.

BRASIL. Lei 8.069 de 13 de julho de 1990. Dispõe sobre o Estatuto da Criança e do Adolescente e dá outras providências. Diário Oficial da União, Brasília.

COELHO, Patrícia Margarida Farias (2011). Advergame "erótico: uma estratégia de sedução publicitária". Semeiosis. São Paulo, (2), 1-16.

COELHO, Patrícia Margarida Farias; COSTA, Marcos Rogério Martins; FONTANARI, Rodrigo (2016). "O parecer do sentido: perspectiva semiótica”. Razón y Palabra. Monterrey, 20 (92), 1-18.

DAMÁSIO, Antonio R (1996). O erro de Descartes: emoção, razão e o cérebro humano. São Paulo: Companhia das Letras.

DANTAS, Heloisa (1992). "A afetividade e a construção do sujeito na psicogenética de Wallon". In: DE LA TAILLE, Yves; OLIVEIRA, Marta K.; DANTAS, Heloisa. Piaget, Vygotsky e Wallon. Teorias psicogenéticas em discussão. São Paulo: Summus.

FONTANILLE, Jacques (2008). Semiótica do Discurso. Jean Crittus Portela (Trad.). São Paulo: Contexto.

FREIRE, Roberto (2015). Namoro on-line: 10 curiosidades sobre o Par Perfeito. TechTudo. In http://www.techtudo.com.br/noticias/ noticia/2015/03/namoro-online-lista-tem-10-curiosidades-sobre-o- 
parperfeito.html. Acesso em 03.Mai.2016.

GREIMAS, Algirdas Julien; COURTÉS, Joseph (2008). Dicionário de semiótica. São Paulo: Contexto.

GREIMAS, Algirdas Julien; FONTANILLE, Jacques. (1994). Semiótica das paixões: dos estados de coisa aos estados de alma. Tradução de Maria José Rodrigues Coracini. São Paulo: Ática.

HOUAISS, Antonio (2014). Dicionário Houaiss da Língua Portuguesa. Rio de Janeiro: Objetiva.

PAR PERFEITO. In https://www.parperfeito.com.br/. Acesso em 1.Mai.2016.

PRENSKY, Marc (2001a). "Digital natives, digital immigrants". In: PRENSKY, Marc. On the Horizon. MCB University Press, 9 (5), October. In http:// www.marcprensky.com/writing/. Acesso em 01.Mai.2016.

ROCHA, Cleomar; SANTAELLA, Lucia (Orgs.) (2015). A onipresença dos jovens na rede. Goiânia, GO: FUNAPE: MEDIA LAB/ CIAR UFG/ GRÁFICA UFG, p.264.

SALGADO, Marcelo de Mattos (2015). A gamificação do romance entre os jovens. p.49-69.

SANTAELLA, Lucia (2007). Linguagens líquidas na era da mobilidade. São Paulo: Paulus. Introdução e capítulos 1, 7, 16 e 17.

(1996). Cultura das Mídias. São Paulo: Experimento.

SAUSURRE, Ferdinand de. (2013). Curso de linguística geral. Charles Bally e Albert Sechehaye (Orgs). São Paulo: Cultrix.

Roseli de Lourdes Gomes é Mestranda em Ciências Humanas da Universidade de Santo Amaro-UNISA/campus II. Membro do Grupo de Estudos Interdisciplinares em Educação - GEITE. E-mail: rosegomescv@ gmail.com. 